\title{
VALUTAZIONE DELLA CAPACITÀ \\ DISCRIMINANTE DELLE REGIONI I6S, Hsp65, ITS E 23S DEL GENOMA DEL GENERE MYCOBACTERIUM
}

\author{
Russo C.', Tortoli E. ${ }^{2}$ De Florio L.'., Coltella L.'., \\ Menichella D. .' \\ 'Unità Operativa di Microbiologia \\ Ospedale Pediatrico Bambino Gesù, I.R.C.C.S. - Roma \\ ${ }^{2}$ Centro di Riferimento per i Micobatteri della Regione Toscana- \\ Ospedale Careggi- Firenze
}

\section{Introduzione.}

Alcune specie di micobatteri non tubercolari (NTM) sono prevalentemente ambientali; al contrario per altri NTM è stata accertata l'associazione a stati morbosi, anche importanti, come patogeni opportunisti.

Motivi epidemiologici e clinici, in primo luogo il diverso spettro di sensibilità agli antibiotici, richiedono una esatta identificazione dei NTM isolati. Fino a qualche anno fa l'identificazione dei NTM sembrava facilmente attuabile con un limitato pannello di test biochimici e colturali.

Questa convinzione era supportata da una scarsa conoscenza della tassonomia dei micobatteri che riconosceva solo 30 specie.

Il peso crescente della genetica negli studi tassonomici ha minato questa convinzione determinando un rapido incremento nel numero di specie di micobatteri riconosciute (attualmente $92+5$ in attesa di convalida).

\section{Metodi.}

In questo studio sono stati analizzati oltre 100 ceppi di micobatteri. Per tutti i ceppi è stato sequenziato in primo luogo il gene $16 \mathrm{~S}$, codificante per l'rRNA $16 \mathrm{~S}$, che costituisce il "gold standard". Gli scarsi polimorfismi della sequenza $16 \mathrm{~S}$ all'interno del genere Mycobacterium, in alcuni casi non consentono la discriminazione tra specie strettamente correlate. Per superare questo inconveniente gli stessi ceppi sono stati sequenziati per la regione del gene $h s p$ 65, e per la regione ITS-23S. Ad hoc, sono stati costruiti i database delle sequenze ottenute.

\section{Risultati.}

Entrambi i loci hanno fornito uno strumento di caratterizzazione tassonomica. Le analisi filogenetiche condotte con il metodo di Neighbor-Joining e di parsimonia Maximun-likelood hanno consentito una efficiente caratterizzazione tassonomica che ha permesso di evidenziare un maggior potere discriminante tra clades e sottoclades della regione ITS-23S rispetto alla regione del locus $h s p 65$.

\section{Conclusioni.}

I metodi automatici di sequenziamento, forniscono risultati rapidi e riproducibili il sequenziatore può essere usato anche per altre identificazioni batteriche; il TAT (Turn Around Time) si misura in ore e non in settimane; l'ottimizzazione del target selezionato, mediante disegno ottimizzato di primers, puo' fornire regioni ancora piu' "tipizzanti", L'informazione clinica, così come la determinazione della sensibilità agli antibiotici, aiutano a riempire progressivamente le grandi lacune relative alla conoscenza delle malattie associate ai MNT. 